\title{
ANÁLISIS JURISPRUDENCIAL DE LA APLICACIÓN DE LOS TRATADOS DE DERECHOS HUMANOS EN RECURSOS DE PROTECCIÓN (1989 - 2010)
}

\author{
Miriam Henríquez Viñas ${ }^{1}$ \\ Profesora Derecho Constitucional \\ Universidad de Talca - Chile \\ mihenriquez@utalca.cl
}

\section{INTRODUCCIÓN}

El presente trabajo tiene como objetivo principal analizar la aplicación de los tratados internacionales de derechos humanos por las Cortes de Apelaciones del país en sede de protección. Como puede observarse, generalmente, la doctrina nacional ha abordado el tema de la aplicación de los tratados centrando su atención en la problemática de su jerarquía. Sin embargo, corresponde adelantar que las Cortes de Apelaciones del país han invocado en sus fallos ciertos y determinados tratados internacionales sobre derechos humanos, con distintos fines, excepcionalmente enfrentando conflictos normativos en los cuales deba resolver conforme al principio de jerarquía normativo, distinguiéndose los casos en que: a) se los cita para reforzar sus argumentos; b) para complementar el contenido de los derechos constitucionales vulnerados o en conflicto; c) como parámetro de ilegalidad, en cuyo caso podría plantearse un conflicto normativo entre un tratado internacional y una norma interna. La citada distinción será la que nos permita avanzar en el desarrollo de este análisis jurisprudencial.

Para la consecución de tal objetivo propuesto analizaremos los fallos que invocan en sus considerandos y resoluciones a los tratados internacionales de derechos humanos, particularmente la jurisprudencia emanada de las Cortes de

\footnotetext{
${ }^{1}$ Abogado, Universidad Nacional del Comahue, Argentina. Magíster en Derecho Público con mención en Derecho Constitucional, Pontificia Universidad Católica de Chile. Doctor en Ciencias Jurídicas, Universidad de Santiago de Compostela, España. Profesora de Derecho Constitucional de las Universidades de las Américas Andrés Bello y Alberto Hurtado. Profesora del Magíster en Derecho Constitucional y Derechos Humanos del Centro de Estudios Constitucionales de la Universidad de Talca. Profesora del LL. M en Derecho de la Pontificia Universidad Católica de Chile. Email mihenriquez@utalca.cl
} 
Apelaciones del país recaída en primera instancia en recursos de protección, durante el período 1989 (año de la primera reforma constitucional a la Constitución de 1980 y que incorporó la segunda parte al artículo $5^{\circ}$ inciso segundo) hasta junio del año 2010.

\section{TRATADOS DE DERECHOS HUMANOS INVOCADOS PARA REFORZAR LOS ARGUMENTOS DE LA SENTENCIA}

Constituye un ejemplo de este primer grupo, el caso Andrónico Luksic con Francisco Martorell, de 1993, conocido por la Corte de Apelaciones de Santiago². $\mathrm{El}$ recurso de protección fue interpuesto por don Andrónico Luksic en contra de don Francisco Martorell y don Jorge García Arenas, representante este último de la Editorial Planeta, por la supuesta conculcación del derecho previsto en el artículo 19 No 4 de la Carta Fundamental. Indicó el recurrente que la publicación de los instrumentos que habrían servido para fraguar el delito de extorsión, recopilados en el libro Impunidad Diplomática, constituye un acto ilícito tipificado en el Código Penal y en la Ley No 16.643 sobre Abuso de Publicidad, y arbitrario, lesionando los derechos amparados en el artículo 19 No 4 de la Constitución. Solicitó en consecuencia al tribunal, como medida preventiva, prohibir el ingreso del libro al país, sin perjuicio de que en definitiva se adopten las providencias que se juzguen necesarias.

La Corte de Apelaciones estimó que en el caso se había dado un conflicto de derechos fundamentales, puntualmente entre el derecho a la protección de la vida privada y la honra, del 19 No 4; y la libertad de expresión, del 19 No 12 de la Constitución. Resolvió tal conflicto con base en la llamada "tesis numerológica", es decir, atribuyó más importancia a los derechos consagrados en el artículo 19 No 4, por estar más cercano al núcleo esencial de la persona, que aquél previsto en el artículo 19 No 12 de la Constitución. Tal conclusión puede observarse en el Considerando No 8: "Nadie discute que el constituyente siguió, aunque no lo diga expresamente, un orden de prelación en las garantías y derechos que consagra el artículo 19. Desde luego, la ordenación en que aborda tales derechos y garantías no es arbitraria, como lo prueba la sucesión descendente de su importancia. Así, se comienza con la vida y la integridad personal, luego la igualdad ante la ley, después la igual protección ante la ley y en seguida, en el número 4 la honra, en circunstancia que la libertad de información está contemplada en el número 12".

Así, la Corte de Apelaciones buscó mayores fundamentos a su conclusión en lo dispuesto por los tratados internacionales. Esto se evidencia en lo dispuesto por el

\footnotetext{
${ }^{2}$ Corte de Apelaciones de Santiago, Rol No 983-93, 15 de junio de 1993.
} 
Considerando No 9: "Que lo concluido en los considerandos anteriores es plenamente coherente con lo dispuesto en los tratados internacionales sobre derechos esenciales que emanan de la naturaleza humana, ratificados por Chile y vigentes en nuestro pais, siendo suficiente para esta magistratura citar al efecto los artículos 17 y 19 números 2 y 3 del Pacto Internacional de Derechos Civiles y Politicos, los cuales al tratar estos derechos confieren manifiestamente mayor jerarquia a la privacidad y a la honra que a la libertad de expresión e información. Desde luego permiten la restricción previa, siempre que esté expresamente fijada en la ley y sea necesaria para asegurar el respeto a los derechos o a la reputación de los demás y también a la moral pública, lo que es plenamente aplicable al caso de autos. Todavía más, el artículo $4^{\circ}$ de este Pacto permite en circunstancias excepcionales, que el mismo contempla, suspender o restringir el derecho a la libertad de expresión e información, pero no ocurre lo mismo con la privacidad y la honra, las que deben ser respetadas en toda situación. También cabe mencionar los artículos 11 y 13 de la Convención Americana de Derechos Humanos o Pacto de San José de Costa Rica, que aun cuando contemplan el derecho a la libertad de expresión en forma amplisima, pues no permiten ninguna forma de censura previa, ésta debe interpretarse en los términos señalados en el considerando $7^{\circ}$, teniendo presente que en la especie no se trata de medidas restrictivas dispuestas por el Poder Ejecutivo, que podrian calificarse de politicas, sino de medidas judiciales contempladas en la ley y que corresponden al rol tutelar que es inherente a los Tribunales de Justicia. En consecuencia, no sólo la Constitución Política asigna indiscutiblemente mayor valor a la honra, sino que un instrumento internacional de carácter universal como es el Pacto Internacional de Derechos Civiles y Políticos coincide con ella".

Finalmente corresponde señalar que la Corte de Apelaciones acogió el recurso incoado en contra de Francisco Martorell, prohibiendo la internación y comercialización del libro Impunidad Diplomática, decisión que fue confirmada por la Corte Suprema.

El segundo ejemplo lo conforma el caso Emilia Capella y otra con Juez Tributario de VIII Región, del año 1999, conocido por la Corte de Apelaciones de Concepción. El mismo fue interpuesto por doña Elizabeth Emilfork en representación de doña Emilia Capella Jane y doña Lucía Barraza en contra de don Sergio Jarpa, Juez Tributario VIII Región, fundándose en que en el marco de una causa tributaria, sobre reclamación de liquidaciones, el Juez recurrido habiendo tomado conocimiento de la muerte del contribuyente a quien afectaban las liquidaciones, admitió la actuación de un agente oficioso y exigió la ratificación de lo obrado por éste en el mismo día que fue decretada esa diligencia, omitiendo suspender el procedimiento y notificar a todos sus herederos conforme lo ordena el artículo $5^{\circ}$ del Código de Procedimiento Civil. Habiendo tomado conocimiento las señoras 
Capella y Barraza, en su calidad de herederas testamentarias, de la existencia de la citada causa tributaria, solicitaron en ella la nulidad de lo obrado a fin de que se retrotrajera la causa al estado de notificar válidamente a los herederos del contribuyente y permitirles la adecuada defensa de sus derechos, lo que fue denegado por el Juez Tributario. Tal acto, a juicio de las recurrentes constituyó uno ilegal por no dar aplicación al artículo $5^{\circ}$ del Código de Procedimiento Civil e infringir los artículos 129 del Código Tributario, que no permite la agencia oficiosa en las reclamaciones tributarias, y 2163, No 5 del Código Civil. Además, a juicio de las actores, dicha decisión es al mismo tiempo arbitraria y conculca su derecho de propiedad.

La Corte de Apelaciones de Concepción comenzó la resolución del caso cuestionándose la procedencia del recurso de protección respecto de resoluciones judiciales. Buscó la respuesta indagando en la doctrina nacional, en los antecedentes de la Constitución de 1980, en la jurisprudencia de los tribunales superiores y concluyó sobre su procedencia. Corroboró y fundamentó su postura con la mención al contenido de ciertos tratados internacionales, como el Pacto de los Derechos Civiles y Políticos y la Convención Americana sobre Derechos Humanos que consagran el derecho a un recurso sencillo, rápido y efectivo que ampara a las personas de actos que violan los derechos, aun cuando tal violación es cometida por quienes actúan en ejercicio de sus funciones oficiales. Puntualmente señaló: "Quinto: Que la procedencia y extensión asi reconocida para el recurso de protección es concordante con lo previsto en los siguientes Tratados Internacionales: a) La Declaración Universal de los Derechos del Hombre, que asegura a toda persona ser oída en condiciones de plena igualdad por el tribunal pertinente para la determinación de sus derechos y obligaciones (artículo 10). b) El Pacto Internacional de Derechos Civiles y Políticos, adoptado por la Asamblea General de las Naciones Unidas por Resolución No 2.200, el 16 de diciembre de 1966, suscrito por Chile en esa misma época y mandado a cumplir como ley de la República por Decreto No 778, del Ministerio de Relaciones Exteriores, de 30 de noviembre de 1976, publicado en el Diario Oficial de 29 de abril de 1989, en cuanto obliga a los Estados permitir a toda persona que sufra violación de sus derechos o libertades allí consignadas, el ejercicio de un recurso efectivo, aun cuando tal violación hubiera sido cometida por personas que actuaban en ejercicio de sus funciones oficiales (artículo $2^{\circ}, N^{\circ} 3$, letra a), entre las que se encuentra la igualdad ante los tribunales y el derecho a ser oído con las debidas garantías por el tribunal competente en la determinación de sus derechos u obligaciones de carácter civil (artículo 14). c) La Convención Americana sobre Derechos Humanos, denominada Pacto de San José de Costa Rica, que reconoce que toda persona tiene derecho a un recurso sencillo y rápido (...) que la ampare contra actos que violen sus derechos fundamentales reconocidos por 
la Constitución, la ley o la presente Convención, aun cuando tal violación sea cometida por personas que actúen en ejercicio de sus funciones oficiales (articulo 25), entre cuyos derechos se encuentra el de ...ser oída, con las debidas garantías y dentro de un plazo razonable, en la determinación de sus derechos y obligaciones de orden civil, laboral, fiscal o de cualquier otro carácter (artículo 80, No 1)".

La Corte de Apelaciones acogió el recurso fundado en la conculcación del derecho de propiedad de las recurrentes; sin embargo, la Corte Suprema revocó la sentencia apelada ${ }^{3}$.

En un sentido similar, es decir acogiendo un recurso de protección contra resoluciones judiciales, la Corte de Apelaciones de Concepción resolvió el caso Juan Giacamán Compañia Ltda. con Juez Primer Juzgado Trabajo Concepción y Juez Segundo Juzgado Civil Concepción, del año 2004́. El recurrente interpuso la acción de protección contra dos resoluciones judiciales, la primera dictada por el Magistrado del Primer Juzgado del Trabajo de Concepción, quien ordenó el embargo y posterior inscripción de un inmueble de propiedad de un tercero que no era parte en la causa; la segunda contra la resolución dictada por el Juez del Segundo Juzgado Civil de Concepción que no hizo ningún análisis sobre la negativa del Conservador de Bienes Raíces a practicar la inscripción del embargo. La Corte de Apelaciones resolvió acoger el recurso de protección, fundada en la conculcación de los derechos constitucionales previstos en el artículo 19 No 3 y 24, argumentando también su decisión en lo previsto por los tratados internacionales, a los que se refiere sólo para complementar el argumento principal. Así concluyó: "Por estas consideraciones, lo dispuesto en los artículos 21 y 25 de la Convención Americana sobre Derechos Humanos; artículo $2^{\circ}$ del Pacto Internacional de Derechos Civiles y Políticos; 5o, 6o, $19 N^{\circ} 3$ y 24 y 20 de la Constitución Política de la República; $1^{\circ}$ del Código Orgánico de Tribunales y lo preceptuado en el Auto Acordado de la Excma. Corte Suprema sobre Tramitación del Recurso de Protección de Garantías Constitucionales, se declara: que se acoge el recurso de protección interpuesto por don Juan Carlos Giacamán Giacamán, en lo principal del escrito de fojas 48, sólo en cuanto se declara que las resoluciones dictadas en las causas roles Nos. 3502-2001 del Primer Juzgado del Trabajo de Concepción y 455-2003 del Segundo Juzgado Civil de Concepción que ordenaron el embargo y posterior inscripción en el Registro de Interdicciones y Prohibiciones de Enajenar del bien raiz de su dominio, no le empecen mientras en instancia procesal válida no se declare otra cosa. Asimismo se ordenará al señor Conservador de Bienes Raices la cancelación y alzamiento del embargo inscrito

\footnotetext{
${ }^{3}$ Corte Suprema, Rol N 4610-1999, 19 de enero de 2000.

${ }^{4}$ Corte de Apelaciones de Concepción, Rol No 558-2004, 23 de agosto de 2004.
} 
a fojas 472 No 300 del Registro de Interdicciones y Prohibiciones de Enajenar del año 2004 y la subinscripción al margen de la inscripción de dominio de fojas $367 N^{\circ} 387$ del Registro de Propiedad del año 1989". Tal sentencia fue apelada y revocada por la Corte Suprema con fecha 23 de noviembre de 2004.

Como cuarto y último ejemplo, del año 2008, corresponde mencionar el caso Colegio de Periodistas contra Jueza del Séptimo Juzgado de Garantía. En tal ocasión, el Colegio de Periodistas interpuso un recurso de protección contra doña Cecilia Pasten, Jueza del Séptimo Juzgado de Garantía de Santiago, quien dictó en la audiencia de formalización la orden de prohibir la divulgación del nombre, imagen y fotografía del imputado, fundada en el derecho a la privacidad y principio de inocencia de éste ${ }^{5}$. Los recurrentes estimaron que por este acto la jueza cometió un acto ilegal y arbitrario, que afecta su derecho a la libertad de expresión del artículo 19 No 12 y que, además, se conculcaron los derechos a la igualdad y a la protección del trabajo del artículo 19 No 2 y 16, respectivamente, de la Constitución. Los recurrentes citaron lo dispuesto en el artículo 19 No 2 del Pacto de los Derechos Civiles y Políticos, el artículo 13 de la Convención Americana sobre Derechos Humanos, la jurisprudencia de la Corte Interamericana de Derechos Humanos referida a la colegiatura obligatoria de periodistas, dando relevancia a la libertad de expresión para la existencia de la democracia.

La Corte de Apelaciones de Santiago acogió el recurso contra la resolución impugnada que prohibió la difusión del nombre y fotografía del imputado, considerando que dicho acto fue ilegal y que afectó la garantía constitucional alegada por los recurrentes sin hacer mención alguna al derecho de emitir opinión o información sin censura previa según lo previsto por los tratados internacionales. Sin perjuicio de ello, la Corte invocó en el Considerando Undécimo ciertos tratados internacionales con el objeto de reforzar sus argumentos sobre el principio de presunción de inocencia previsto en el artículo $4^{\circ}$ del Código Procesal Penal. Así señaló: "110) Que, uno de los elementos que ha tenido como fundamento la resolución recurrida, es salvaguardar la presunción de inocencia del imputado, contenida en el artículo $4^{\circ}$ del Código Procesal Penal, disposición ubicada dentro de los principios básicos que rigen el nuevo procedimiento penal. Esta presunción de inocencia se encuentra reconocida, además, en diversos Tratados Internacionales suscritos por Chile, entre ellos el Pacto Internacional de Derechos Civiles y Politicos y la Convención Interamericana de Derechos Humanos, conocida como Pacto de San José Costa Rica. Todas estas disposiciones, establecen el derecho de las personas a ser consideradas inocentes de la comisión de cualquier delito, mientras no se establezca legalmente su culpabilidad, esto

\footnotetext{
${ }^{5}$ Corte de Apelaciones de Santiago, Rol No 3.207-2008, 28 de octubre de 2008.
} 
es, mediante una sentencia condenatoria dictada por un Tribunal. 12o) Que, unido estrechamente a este concepto de presunción de inocencia del imputado, el sistema procesal penal chileno y los tratados internacionales suscritos y ratificados por nuestro pais, reconocen una serie de derechos a este imputado, que le permiten no sólo actuar dentro del procedimiento penal, sino también, ser sujeto de medidas dispuestas por la autoridad destinadas a proteger sus derechos".

De lo analizado, puede observarse que varias sentencias recaídas en sede de protección han invocado los tratados de derechos humanos para reforzar sus argumentos, fundamentalmente respecto al derecho de libertad de expresión, derecho a un recurso expedito y rápido de amparo y presunción de inocencia. En ninguno de estos casos las Cortes de Apelaciones debieron resolver conflictos normativos, toda vez que el tratado era concordante con la normativa nacional.

\section{COMPlementación DEL CONTENido DE LOS DERECHOS CONSTITUCIONALES}

Respecto de este segundo grupo de casos, en el cual los tratados internacionales de derechos humanos se invocan con el objeto de ampliar o complementar el contenido de un derecho constitucional, corresponde destacar el caso Patricia Vásquez con Fonasa ${ }^{6}$. La Corte de Apelaciones de Santiago, en el recurso interpuesto por doña Patricia Elena Vásquez, ante la negativa de Fonasa de proporcionar el medicamento Herceptin para el tratamiento del cáncer de mama, hizo referencia a una serie de asuntos antes de resolver el recurso: a) señaló que la finalidad del Estado es el bien común (Considerando segundo); b) que es deber de los órganos del Estado respetar y promover los derechos fundamentales (Considerando tercero); c) que los derechos constitucionales amagados en el caso concreto son el derecho a la vida y a la integridad física y psíquica y el derecho a la protección de la salud. Sobre este último la Corte de Apelaciones realizó un interesante razonamiento, señalando: "Que si bien esta última garantía, del número 9 en la parte transcrita, no se encuentra amparada por el recurso de protección según lo establece el artículo 20, si constituye un derecho garantizado a todas las personas por la Carta Primera, por lo que no es posible desentenderse de su existencia para una adecuada administración de justicia." (Considerando cuarto).

Luego, en el Considerando quinto la Corte de Apelaciones de Santiago hizo referencia al Pacto Internacional de los Derechos Económicos, Sociales y Culturales, puntualmente en su artículo 12, que trata sobre el derecho a la salud, evidenciándose que su referencia tuvo como objeto complementar el contenido

${ }^{6}$ Corte de Apelaciones de Santiago, Rol No 7766-2009, 24 de noviembre de 2009. 
del derecho constitucional del artículo 19 No 9 de la Constitución. Tal conclusión se desprende de la redacción de la sentencia que se detiene en las medidas que debe adoptar el Estado para asegurar este derecho, entre las que destacan las necesarias para la prevención y el tratamiento de enfermedades, la creación de condiciones que aseguren a todos la asistencia y servicios médicos. En palabras de la Corte: "Que, por último, el Decreto Supremo No 326, del Ministerio de Relaciones Exteriores, publicado en el Diario Oficial de 27 de mayo de 1989, promulga el Pacto Internacional de Derechos Económicos, Sociales y Culturales adoptado por la Asamblea General de la Organización de las Naciones Unidas, el 19 de diciembre de 1966, suscrito por Chile el 16 de septiembre de 1969; que en su artículo 12 dispone: "1. Los Estados Partes en el presente Pacto reconocen el derecho de toda persona al disfrute del más alto nivel posible de salud fisica y mental. 2. Entre las medidas que deberán adoptar los Estados Partes en el Pacto a fin de asegurar la plena efectividad de este derecho, figurarán las necesarias para: ...c) La prevención y el tratamiento de las enfermedades epidémicas, endémicas, profesionales y de otra indole, y la lucha contra ellas; d) La creación de condiciones que aseguren a todos asistencia médica y servicios médicos en caso de enfermedad". De conformidad a lo ya expresado en el motivo tercero, este Pacto y el derecho consignado precedentemente constituye uno esencial que emana de la naturaleza humana y como tal es deber del Estado respetarlo y promoverlo". (Considerando Quinto).

Finalmente, cabe decir que la Corte de Apelaciones de Santiago acogió el recurso de protección, razonando que la negativa de Fonasa y del Ministerio de Salud a proporcionar el medicamento Herceptin es arbitrario e ilegal y vulnera las garantías constitucionales del derecho a la vida y a la protección a la salud, ordenando proporcionar el medicamento a la recurrente. Tal sentencia fue confirmada por la Corte Suprema ${ }^{7}$.

Como puede observarse, en casos como el destacado, los tribunales de alzada no han debido resolver conflictos normativos, toda vez que los tratados de derechos humanos sólo complementan los derechos y garantías constitucionales o amplían sus contenidos.

\section{TRATADOS INTERNACIONALES COMO PARÁMETRO DE ILEGALIDAD}

En el caso Mariano Puelman Nanco y otros contra Corema de la Araucanía, del año $2010^{8}$, don Mariano Puelman Nanco y Manuel Rivera Huilipán interpusieron un recurso de protección contra la Resolución Exenta No 242 de 9 de octubre

\footnotetext{
${ }^{7}$ Corte Suprema, Rol No 9.317-2009, 28 de enero de 2010.

${ }^{8}$ Corte de Apelaciones de Temuco, Rol No 1.705-2009, 21 de enero de 2010.
} 
de 2009 de la Corema de la Araucanía, por la cual se calificó favorablemente la Declaración de Impacto Ambiental del Proyecto Piscicultura Palguin, considerando dicho acto como arbitrario e ilegal, que amenaza sus derechos a la vida, a la igualdad, a vivir en un ambiente libre de contaminación, a la salud, a desarrollar una actividad económica y de propiedad.

La Corte de Apelaciones de Temuco en tal ocasión estimó que lo que jurídicamente corresponde analizar es si hubo por parte de la autoridad administrativa ilegalidad o arbitrariedad al dictar la Resolución No 242 antes citada, en cuanto debió o no considerar el trámite de la consulta al tenor de lo dispuesto en el artículo $6^{\circ}$ No 1 letra a) y No 2 y artículo $7^{\circ}$ No 1 del Convenio 169 de la OIT y el artículo 34 de la Ley No 19.253, conocida como Ley Indígena.

La Corte desarrolló en sus considerandos las siguientes afirmaciones: a) el Convenio No 169 de la OIT contiene normas autoejecutables o de aplicación directa; b) sus normas son de Derecho interno y, por tanto, deben ser aplicadas por la autoridad atendiendo al principio de juridicidad y en un sentido más amplio tributario del concepto de Estado de Derecho; c) el Convenio No 169 de la OIT viene a enriquecer la Ley Indígena, perfeccionando y llenando de contenido el artículo 34 de la ley, referido a las consultas a los pueblos indígenas respecto de medidas legislativas y administrativas susceptibles de afectarles directamente.

Luego, la Corte de Apelaciones de Temuco concluyó que el acto de la Corema, la Resolución No 242 de 2009, es ilegal toda vez que contraviene lo dispuesto por el tratado internacional, esto es, el Convenio OIT No 169. Así expresó en el Considerando No 10: “(...) la autoridad no se ha ceñido a la legislación vigente que son las normas autoejecutables del Convenio -indicado- en cuanto debió llamar a la consulta respectiva en los términos que señala el Convenio y no a simples actos denominados de sociabilización que distan mucho en forma y contenido de lo que pretende el Convenio 169 vigente en nuestra legislación interna".

Así, la Corte de Apelaciones de Temuco acogió el recurso de protección en contra de la Corema de la Araucanía, dejando sin efecto la Resolución Exenta No 242 referida y dispuso que la autoridad para calificar la Declaración de Impacto Ambiental debe realizar la consulta a las comunidades recurrentes como lo establece el artículo $6^{\circ}$ No 1 letra a) del Convenio 169.

Por otro lado, en el caso Alumnos de la Escuela Blanco Lepin con Policía de Investigaciones ${ }^{9}$, del año 2010, doña Karina Riquelme interpuso un recurso de protección a favor de dos niños, quienes fueron interrogados en tono burlesco y amedrentador por dos personas presumiblemente pertenecientes a alguna de las

${ }^{9}$ Corte de Apelaciones de Temuco, Rol No 545-2010, de 13 de mayo de 2010. 
secciones de inteligencia de las policías, siendo los recurridos la Prefectura de Carabineros de Cautín y la Policía de Investigaciones de Chile. La recurrente estimó amagados el derecho a la integridad psíquica de los niños y a la igualdad, con base en lo dispuesto en el artículo $19 \mathrm{No}^{\circ}$. 1 y 3 de la Constitución. Invocó, además, la recurrente la vulneración de los derechos reconocidos en la Convención sobre los Derechos del Niño, el Pacto Internacional de los Derechos Civiles y Políticos y el Pacto Internacional de los Derechos Económicos, Sociales y Culturales.

La Corte de Apelaciones de Temuco falló acogiendo el recurso en contra de la Policía de Investigaciones de Chile, fundada en que los actos de la Policía de Investigaciones conculcaron el derecho a la integridad psíquica de los niños y señaló que el actuar de la Policía de Investigaciones debe respetar los derechos consagrados en los tratados que enumera. Da cuenta de lo afirmado lo resuelto por el tribunal en el Considerando 70, que dice: "Que las obligaciones anteriores de los funcionarios de la Policía de Investigaciones adquieren mayor fuerza por cuanto, tratándose de un órgano estatal, deben respetar y promover los derechos esenciales que emanan de la naturaleza humana, garantizados por la Constitución Politica de la República asi como por los tratados internacionales ratificados por Chile y vigentes (inc. $2^{\circ}$ del Art. $5^{\circ}$ de la Carta Fundamental). Por consiguiente, deben brindar protección a todos los menores sin discriminación alguna (Art. 24 del Pacto de Derechos Civiles y Políticos y 10 del Pacto de Derechos Civiles, Sociales y Culturales). Del mismo modo, al proceder como lo hicieron, los recurridos no tuvieron presente lo dispuesto en el artículo $3^{\circ}$ de la Convención sobre Derechos del Niño, que obliga a las instituciones públicas o privadas a tener como consideración primordial atender el interés superior del niño, asegurando la protección y el cuidado que sean necesarios para su bienestar; y el artículo 19 del mismo instrumento internacional, que impone el deber de proteger al niño contra toda forma de perjuicio o abuso físico o mental, descuido o trato negligente o malos tratos. $8^{\circ}$.- Que por lo anteriormente expuesto, la actuación ya referida constituye una perturbación o amenaza a la integridad psíquica de los niños en cuyo favor se ha recurrido, garantizada en el numeral $1^{\circ}$ del Art. 19 de la Carta Política, por lo que la acción constitucional deducida será estimada, como se dirá en lo resolutivo".

Sin embargo, llama la atención que la Corte de Apelaciones de Temuco no refirió si los actos que conculcaron el derecho a la integridad psíquica revisten las características de ser ilegales o arbitrarios; empero, parece derivar la ilegalidad de dichos actos de su contravención a los tratados internacionales invocados. Esto último se deduce de la siguiente decisión: "Y visto lo dispuesto en el artículo 20 de la Constitución Politica de la República y Auto Acordado de la Excma. Corte Suprema sobre la materia, se declara que HA LUGAR al recurso interpuesto por doña Karina 
Riquelme Viveros, a favor de los niños Karla Jazmin Reyes Cayupán y Victor Manuel Cayupán Niripil, en contra de la Policía de Investigaciones de Chile, sólo en cuanto ésta deberá abstenerse en lo sucesivo de efectuar requerimientos e interrogaciones a los niños en cuyo favor se recurre, bajo cualquier modalidad, sin respetar los preceptos que a favor de éstos garantiza la Convención de Derechos del Niño antes citada".

Estos casos nos plantean la siguiente interrogante: ¿Las Cortes de Apelaciones estiman que ilegalidad significa contrario a la ley y, por tanto, al tratado internacional como norma con jerarquía y valor de ley? O, por el contrario, ¿las Cortes de Apelaciones estiman que ilegalidad implica un acto contrario al ordenamiento jurídico y, por tanto, contrario al tratado internacional como una fuente distinta a la ley y con mayor jerarquía que la legal?

Para resolver tales interrogantes corresponde aclarar ciertas cuestiones sobre la jerarquía como criterio de resolución de conflictos normativos y las tesis sobre las jerarquías de los tratados.

\section{A. Los conflictos normativos y la jerarquía como método de resolución}

Las antinomias o conflictos normativos son inevitables en un ordenamiento jurídico por razón de su dinamismo y la diversidad de poderes normativos que coexisten en los ordenamientos complejos ${ }^{10}$. En este caso, la solución al problema de las antinomias debe basarse en la aplicación de los distintos principios o criterios que ordenan el Sistema de Fuentes y que determinan el Derecho aplicable ${ }^{11}$. La resolución de los conflictos normativos se logra mediante la aplicación de distintos criterios, algunos de los cuales son: jerarquía, cronológico, especialidad, competencia y prevalencia.

El criterio jerárquico, el que nos interesa, es aquel según el cual la norma de rango superior, en caso de conflicto normativo, prevalece sobre la de rango inferior.

En relación con los tratados de derechos humanos y su aplicación, puede ocurrir que el tratado respecto de otras fuentes del Derecho interno, tales como la ley, el decreto con fuerza de ley, el reglamento y hasta la propia Constitución, sea: a) concordante; b) complementario, por consagrar derechos y garantías que las normas nacionales no prevén o por contemplar facultades o dimensiones de los derechos no reconocidas internamente; c) contradictorio.

\footnotetext{
${ }^{10}$ El conflicto normativo es aquella situación de incompatibilidad que se produce entre dos normas que pertenecen al mismo ordenamiento y tiene el mismo ámbito de validez, en virtud de la cual la aplicación de una de las normas conduce a resultados contrarios a los que se generan con la aplicación de la otra. BobBiO (1987), pp. 201-202.

${ }^{11}$ Henríquez (2009), p. 10.
} 
Sólo en el último caso, es decir, cuando el tratado contradice lo dispuesto por otra fuente del Derecho interno, es posible constatar un conflicto normativo, y sólo en la medida que se cumplan los siguientes requisitos: a) que se trate de dos normas (al menos) que contemplen comportamientos lógicamente incompatibles; b) que las dos normas (al menos) pertenezcan al mismo ordenamiento jurídico; c) que las dos normas (al menos) tengan el mismo ámbito de validez en su aplicación. En una norma pueden distinguirse cuatro ámbitos de validez: temporal, espacial, personal y material ${ }^{12}$.

Con relación al primer requisito, que se trate de dos normas que contemplen comportamientos lógicamente incompatibles, podemos decir que existen relaciones de incompatibilidad normativa cuando coinciden en el mismo ordenamiento jurídico y ámbito de aplicación: a) una norma que manda a hacer alguna cosa y una norma que prohíbe hacer esa misma cosa, b) una norma que manda hacer alguna cosa y otra que permite no hacer esa misma cosa, c) una norma que prohíbe hacer alguna cosa y otra que permite hacer esa misma cosa ${ }^{13}$.

Por tanto, sólo podremos reclamar la aplicación del criterio jerárquico para resolver un conflicto normativo entre un tratado con otra fuente del Derecho interno si existe contradicción entre ellos, es decir, una incompatibilidad normativa y en las circunstancias recién referidas.

Sin embargo, como se dijo, la Constitución Política de la República de Chile no ha explicitado la jerarquía de los tratados de derechos humanos en el ordenamiento interno, siendo labor de los órganos jurisdiccionales determinar tal jerarquía mediante la interpretación de las normas constitucionales, fundamentalmente de los artículos $5^{\circ}$ inciso segundo y 54 No 1 inciso quinto, siempre de conformidad con la concepción internacionalista y la noción de Estado democrático de Derecho.

\section{B. Tesis de la jerarquía legal}

La tesis de la jerarquía legal de los tratados se originó en la doctrina y jurisprudencia nacional, principalmente, por la referencia del antiguo artículo 50 No 1 de la Constitución, relativo a la aprobación de los tratados internacionales por el Congreso Nacional, que señalaba: "La aprobación de un tratado se someterá a los trámites de una ley", ergo, el tratado sería ley.

Corresponde observar que esta tesis, ya de retirada, confunde ambas fuentes del Derecho. Esto, a pesar de que indudablemente por naturaleza, origen,

${ }^{12}$ RuIz (2002), p. 39.

${ }^{13}$ Ruiz (2002), p. 45. 
forma, tramitación, promulgación, publicación y efectos jurídicos, los tratados internacionales son una fuente del Derecho distinta que la ley ${ }^{14}$. Sólo a modo de ejemplo, cabe dar cuenta de la distinta naturaleza del tratado y la ley. La ley es un acto jurídico autónomo y unilateral del Estado, esencialmente modificable por la misma voluntad jurídica que lo generó. El tratado se origina en un acuerdo internacional, producido entre Estados soberanos y regido por el Derecho Internacional. No existe ninguna posibilidad de asimilación conceptual entre ley y tratado, ya que son actos de naturaleza distinta, voluntad unilateral uno, acuerdo $b i$ o multilateral el otro, que además se encuentran regidos por sistemas jurídicos distintos. A su vez, la distinta naturaleza de la ley y el tratado fue aclarada por la reforma constitucional de 2005 al artículo 54 No 1 que señaló "en lo pertinente" el tratado quedará sometido a la tramitación de la ley ${ }^{15}$.

Por otro lado, de seguirse la tesis de la jerarquía legal de los tratados, las consecuencias de un eventual conflicto normativo de un tratado internacional con una ley o un decreto con fuerza de ley sólo podría ser zanjado por la aplicación del criterio de temporalidad. Es decir, si la ley o norma con rango legal es posterior dejará sin efecto el tratado internacional anterior que la contradiga. Sin embargo, el cumplimiento de las obligaciones internacionales obliga a desechar esta solución, principalmente por lo dispuesto en el artículo 27 de la Convención de Viena sobre el Derecho de los Tratados, que dispone: "Una parte no podrá invocar las disposiciones de su derecho interno como justificación del incumplimiento de un tratado. Esta norma se entenderá sin perjuicio de lo dispuesto en el artículo 46".

\section{Tesis de la jerarquía supralegal}

La jerarquía supralegal de los tratados comenzó a predicarse en Chile básicamente a partir de la reforma constitucional de 1989, que incorporó la segunda parte al segundo inciso del artículo 5, agregando: "Es deber de los órganos del Estado respetar y promover tales derechos garantizados por esta Constitución, asi como por los tratados internacionales ratificados por Chile y que se encuentren vigentes".

En el contexto de la referida reforma constitucional, se ha sostenido que la misma tuvo por finalidad robustecer la posición que los tratados de derechos humanos tenían en el ordenamiento jurídico nacional. Así autores como Bertelsen Repetto consideran que la finalidad de la reforma fue consagrar el deber de los órganos del Estado de respetar y promover los derechos humanos garantizados

${ }^{14}$ Henríquez (2007) a), pp. 121-122.

${ }^{15}$ Henríquez (2007) b), p. 319. 
explícitamente en la propia Constitución, e innovó en establecer tal deber constitucional de respeto y promoción de cara a los derechos garantizados en tratados internacionales ratificados por Chile y que se encuentran vigentes. Con respecto a la jerarquía concluye que si bien los tratados sobre derechos humanos están subordinados a la Constitución, están por encima de las leyes y otras normas jurídicas de derecho interno ${ }^{16}$. Incluso autores como Cumplido Cereceda sostienen la jerarquía constitucional de los tratados de derechos humanos, argumentando que antes de la reforma los tratados tenían plena validez en Chile, existían todo tipo de tratados celebrados entre Chile y la comunidad internacional; los tribunales chilenos aplicaban el Derecho internacional consuetudinario y los principios generales del Derecho, reconociendo incluso el jus cogens. De modo que el ordenamiento jurídico chileno no requería una disposición como la modificada para darle validez a los tratados que consagraban derechos humanos. Ellos eran válidos desde antes. Concluye el autor que la enmienda tuvo como propósito el "fortalecimiento", el que se logró mediante la incorporación de los tratados sobre derechos humanos a la Constitución, elevando de tal manera la jerarquía de estas fuentes al rango constitucional ${ }^{17}$.

La principal consecuencia de reconocer jerarquía supralegal a los tratados es que un eventual conflicto normativo con la ley o con el decreto con fuerza de ley se resuelve mediante la aplicación del criterio jerárquico, de modo que siempre prevalecerá el tratado sobre la ley o norma con rango legal, sea anterior o posterior a aquél. La Constitución reconoce implícitamente la jerarquía supralegal del tratado cuando señala en el artículo 54 No 1 inciso $5^{\circ}$ que las disposiciones de un tratado sólo podrán ser derogadas, modificadas o suspendidas en la forma prevista en los propios tratados o de acuerdo a las normas generales de derecho internacional. La fuerza pasiva o de resistencia del tratado frente a la ley es la garantía de la primacía del mismo sobre las leyes anteriores o posteriores contrarias a aquél ${ }^{18}$.

\footnotetext{
${ }^{16}$ Bertelsen (1996), p. 221.

${ }^{17}$ Francisco Cumplido, quien participó como representante de la Concertación de Partidos por la Democracia en la Comisión Técnica, asevera: "La intención fue incorporar los tratados sobre Derechos Humanos a la normativa constitucional, porque si no más nos hubiera valido revisar la totalidad del artículo 19 y haber tratado de convenir las reformas específicas de cada punto. La intención positiva del grupo negociador fue actualizar los derechos de las personas de acuerdo a los instrumentos internacionales aprobados. Algún sentido tenía incorporar los tratados internacionales al artículo $5^{\circ}$ de la Constitución, puesto que siempre teníamos como obligación internacional respetar las disposiciones de los Tratados Internacionales que Chile había ratificado y estaban vigentes al momento de la reforma. Esperábamos que la interpretación diera preferencia a la norma sustantiva que mejor asegurar al derecho humano" CumpLido (1996), p. 195.

${ }^{18}$ Henríquez (2009), p. 55.
} 


\section{Tratado y Constitución}

Finalmente, la relación entre el tratado y la Constitución es más compleja, pero habrá que analizarla en el sentido de evitar el conflicto normativo entre ambos mediante el control previo de constitucionalidad.

En el caso de que se observe una incompatibilidad entre tratado y Constitución, el Estado tendrá al menos tres vías a su alcance: a) no seguir adelante con la tramitación del tratado; b) plantear reservas al tratado, en el caso de ser admisibles, y c) reformar la Constitución para que sea concordante con el tratado.

De esta forma, es evidente cómo cobra importancia el control previo y obligatorio de constitucionalidad de todos los tratados, en tanto evita el conflicto normativo entre tratado y Constitución e impide el control represivo de constitucionalidad.

\section{CONCLUSIONES}

Los conflictos normativos son inevitables en un ordenamiento jurídico por razón de su dinamismo y la diversidad de poderes normativos que coexisten en los ordenamientos complejos. En este caso, la solución al problema de las antinomias debe basarse en la aplicación de los distintos principios o criterios que ordenan el Sistema de Fuentes y que determinan el Derecho aplicable. Uno de los criterios que permite la resolución de los conflictos normativos es el jerárquico.

En relación con los tratados de derechos humanos y su aplicación, puede ocurrir que el tratado respecto de otras fuentes del Derecho interno, tales como la ley, el decreto con fuerza de ley, el reglamento y hasta la propia Constitución, sea: a) concordante; b) complementario, por consagrar derechos y garantías que las normas nacionales no prevén o por contemplar facultades o dimensiones de los derechos no reconocidas internamente; c) contradictorio. Sólo podremos reclamar la aplicación del criterio jerárquico para resolver un conflicto normativo entre un tratado con otra fuente del Derecho interno, en el último caso, cuando existe contradicción entre ellos, es decir, una incompatibilidad normativa.

Como es sabido la Constitución Política de la República de Chile no ha explicitado cuál es la jerarquía de los tratados de derechos humanos. Reconocer jerarquía legal a los tratados de derechos humanos importa que un eventual conflicto normativo entre un tratado y una ley u otra norma con jerarquía legal se resuelva mediante la aplicación del criterio de temporalidad. Empero, tal solución es contraria a las obligaciones internacionales asumidas por el Estado de Chile, fundamentalmente, porque es un principio del Derecho Internacional que no se puede invocar disposiciones del Derecho interno como justificación del incumplimiento de un tratado. 
Por otra parte, reconocer jerarquía supralegal a los tratados significa que un eventual conflicto normativo con la ley o con una norma con rango de ley se resuelve mediante la aplicación del criterio jerárquico, de modo que siempre prevalecerá el tratado sobre la ley o norma con rango legal, sea anterior o posterior a aquél. La Constitución reconoce implícitamente la jerarquía supralegal del tratado cuando señala en el artículo $54 \mathrm{~N}^{\circ} 1$ inciso $5^{\circ}$ que las disposiciones de un tratado sólo podrán ser derogadas, modificadas o suspendidas en la forma prevista en los propios tratados o de acuerdo a las normas generales de derecho internacional. La fuerza pasiva o de resistencia del tratado frente a la ley es la garantía de la primacía del mismo sobre las leyes anteriores o posteriores contrarias a aquél.

Por último, la relación entre tratado y la Constitución habrá que analizarla en el sentido de evitar el conflicto normativo entre ambos mediante el control previo de constitucionalidad, cobrando en esta lógica razón la necesidad del control obligatorio de constitucionalidad de tratados.

Analizando lo relativo a la jerarquía de los tratados de derechos humanos en sede de protección puede afirmarse que las Cortes de Apelaciones del país han invocado en sus fallos ciertos y determinados tratados; sin embargo, tales referencias han tenido distinto sentido, distinguiéndose los casos en que: a) se los cita para reforzar sus argumentos; b) para complementar el contenido de los derechos constitucionales vulnerados o en conflicto; c) como parámetro de ilegalidad.

La referencia más frecuente a los tratados de derechos humanos en sede de protección ha sido en el sentido de reforzar los argumentos de la decisión del tribunal, fundamentalmente destacan fallos relativos a libertad de expresión, procedencia de un recurso expedito y rápido respecto de resoluciones judiciales y presunción de inocencia. En ninguno de estos casos las Cortes de Apelaciones debieron resolver conflicto normativos, toda vez que el tratado era concordante con la normativa nacional.

Asimismo, las Cortes de Apelaciones se han valido de los tratados internacionales para complementar el contenido de ciertos derechos constitucionales, principalmente los derechos sociales, como el derecho a la protección de la salud, estableciendo nuevas obligaciones de promoción y protección al Estado. En esta perspectiva, tampoco los tribunales de alzada han debido resolver conflictos normativos, toda vez que los tratados complementan los derechos y garantías constitucionales o amplían sus contenidos.

Por otra parte, las Cortes de Apelaciones han considerado que ciertas conductas son ilegales por ser contrarias a los tratados de derechos humanos, es decir, estiman a los tratados como parámetro o supuesto de ilegalidad en los recursos de protección. Esta consideración de los tratados de derechos humanos como 
parámetro de ilegalidad podría plantear la necesidad de resolver un conflicto normativo entre una norma reglamentaria o legal con un tratado internacional. En tal sentido, y conforme a lo dispuesto particularmente en el artículo $54 \mathrm{~N}^{\circ} 1$ inciso quinto de la Constitución y las disposiciones del Derecho Internacional, corresponde considerar que ilegalidad implica un acto contrario al ordenamiento jurídico y, por tanto, contrario al tratado internacional como una fuente distinta a la ley y con mayor jerarquía que la legal.

\section{BiBLIOGRAFÍA}

Benadava, Santiago (1999): Derecho Internacional Público, 6 (Santiago, Editorial Jurídica ConoSur).

Bertelsen Repetto, Raúl (1996): "Rango Jurídico de los Tratados Internacionales en el Derecho Chileno", en Revista Chilena de Derecho (Volumen 23, No 2 y 3): pp. 211-222.

Bobbio, Norberto (1987): Teoría General del Derecho (Bogotá, Editorial Temis).

Cumplido Cereceda, Francisco (1996): "Alcances de la Modificación del artículo $5^{\circ}$ de la Constitución Política Chilena en Relación a los Tratados Internacionales", en Revista Chilena de Derecho (Volumen 23 No 2 y 3): pp. 255 -258.

Henríquez Viñas, Miriam (2009): Las Fuentes Formales del Derecho (Santiago, Editorial LegalPublishing).

Henríquez Viñas, Miriam (2008): "Jerarquía de los tratados de derechos humanos: análisis jurisprudencial desde el método de casos", en Revista Estudios Constitucionales (Año 6 No 2): pp. 73-119.

Henríquez Viñas, Miriam a) (2007): "Improcedencia del control represivo de constitucionalidad de tratados internacionales", en Revista Estudios Constitucionales (Año 5 No1): pp. 119-126.

HenríqueZ Viñas, Miriam b) (2007): "Los tratados internacionales en la Constitución reformada”, en Revista de Derecho Público (Volumen 67): pp. 313-323.

Kelsen, Hans (1965): Principios de Derecho Internacional Público (Traducción Hugo Caminos y Ernesto C. Hermida, Buenos Aires, Editorial El Ateneo).

Peña Torres, Marisol (2008): "La aplicación del Derecho Internacional de los Derechos Humanos por el Tribunal Constitucional Chileno", en Revista Estudios Constitucionales (Año 6 No 1): pp. 205-222.

Ruiz SANZ, Mario (2002): Sistemas Jurídicos y conflictos normativos (Madrid, Editorial Dykinson). 


\section{JURISPRUDENCIA}

Karla Reyes, Victor Cayupán con Prefectura de Carabineros de Cautín y Policía de Investigaciones de Chile (2010): Corte de Apelaciones de Temuco, 13 mayo 2010 (recurso de protección).

Mariano Puelman Nanco y otros contra Comisión Regional del Medio Ambiente de la Región de la Araucanía (2010): Corte de Apelaciones de Temuco, 21 enero 2010 (recurso de protección).

Patricia Elena Vásquez Ibáñez con Fondo Nacional de Salud (2009): Corte de Apelaciones de Santiago, 24 noviembre 2009 (recurso de protección).

Colegio de Periodistas de Chile A. G. y otros con Juez del Séptimo Juzgado de Garantía de Santiago (2008): Corte de Apelaciones de Santiago, 28 octubre 2008 (recurso de protección).

María Teresa Valenzuela Silva con Isapre Banmédica S.A. (2006): Corte de Apelaciones de Santiago, 6 abril 2006 (recurso de protección).

Carlos Gormaz y Francisco Tapia con Compañia Minera Escondida Ltda. (2005): Corte de Apelaciones de Antofagasta, 8 julio 2005 (recurso de protección). Juan Giacamán Compañia Ltda. con Juez Primer Juzgado Trabajo Concepción; Juez Segundo Juzgado Civil Concepción (2004): Corte de Apelaciones de Concepción, 23 agosto 2004 (recurso de protección).

Emilia Capella Jane; Lucía Barraza Andalaft; con Juez Tributario de VIII Región (1999): Corte de Apelaciones de Concepción, 30 noviembre 1999 (recurso de protección).

Andrónico Luksic Craig; Gonzalo Menéndez Duque; Carmen Ibáñez Soto; con Francisco Martorell; Editorial Planeta Chile S.A. (1993): Corte de Apelaciones de Santiago, 15 junio 1993 (recurso de protección). 